\title{
7 Social Information Use in Foraging Insects
}

\author{
Ellouise Leadbeater and Lars Chittka
}

\section{CONTENTS}

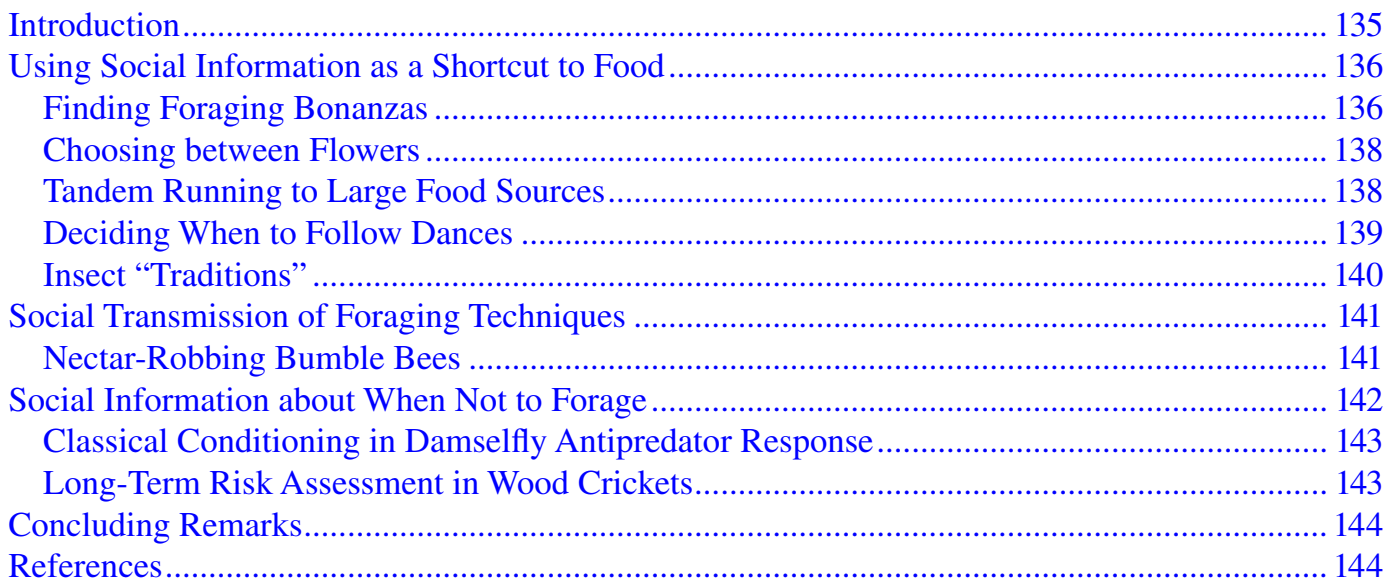

\section{INTRODUCTION}

In 1880, the Victorian naturalist Sir John Lubbock became aware that ants can track their nestmates to rewarding food sources. Lubbock believed that ants were following scent trails, and even went as far as to suggest something approaching a form of chemical language (Lubbock 1882). While he was not so generous about bees- "[Honey] bees do not bring their friends to share any treasure they have discovered" (Lubbock 1882, p. 278) —others were less dismissive. The German pastor Ernst Spitzner wrote of honey bees: "Full of joy, they twirl in circles about those in the hive ... in a few minutes, after these had made it known to the others, they came in great numbers to the place!" (Spitzner 1788; cited in Lindauer 1985, p. 192).

How surprising it is that modern science, with its scorn for anthropomorphism and overinterpretation, has borne out the enthusiastic conjecture that tiny-brained organisms should perform such extraordinary feats of communication! Several decades of rigorous research have uncovered a broad spectrum of social information use in the insects, from subtle cues provided inadvertently by other animals to astoundingly intricate, highly evolved multimodal signals (von Frisch 1967; Hölldobler and Wilson 1990; Dyer 2002; Franks et al. 2002; Nieh et al. 2004; Leadbeater and Chittka 2007a). Despite their small brains, insects show remarkably complex learning abilities (Giurfa 2003; Menzel et al. 2006), and social information often leads to the relatively long-term changes in behavior that constitute social learning. These discoveries have not only enhanced our understanding of insect behavior, but also constituted some of the most influential advances in the 
field of behavioral biology — a fact reflected in the award of the 1973 Nobel Prize for Physiology or Medicine to the pioneering biologist Karl von Frisch.

In this review, our major focus is the contribution that insect studies can make toward understanding the particular circumstances where social information increases biological competitiveness. Like any trait, whether social information use is favored by natural selection will depend upon its costs and benefits relative to the available alternatives, and theory predicts that the balance may often swing in favor of individual exploration (Giraldeau et al. 2002). The question of when and why social information use and social learning may be adaptive has attracted much interest over recent years (Boyd and Richerson 1988; Giraldeau and Beauchamp 1999; Giraldeau et al. 2002; Laland 2004; Kendal et al. 2005), but much of this has failed to touch upon the insect world, which in turn has not made full use of literature arising in other fields. Here, we look at old and new examples of insect social information use with the question "When is social information useful?" in mind.

\section{USING SOCIAL INFORMATION AS A SHORTCUT TO FOOD}

\section{Finding Foraging Bonanzas}

Using social information to locate food potentially offers an economical alternative to the arduous process of individual exploration. Even the simple presence of a foraging conspecific may provide an exploitable, up-to-date cue about a foraging bonanza. However, using social information is not an assured shortcut to success. If food is easy to find, the value of social information will be limited-particularly if gathering it incurs a time cost in itself. For example, although it might intuitively seem that a honey bee should benefit by learning from others about where they have found food, in practice the time cost of waiting for dance information might often outweigh the benefits (Dechaume-Moncharmont et al. 2005; Dornhaus et al. 2006), especially if all foragers choose to wait for social information rather than individually discovering new food patches (Giraldeau and Beauchamp 1999; Dechaume-Moncharmont et al. 2005).

Two recent studies provide an illustration of how food availability and distribution may shape social information systems. Honey bees (Apis mellifera), famously, communicate the location of food sources to recruits in the darkness of the hive via figure-eight dances on the vertical honeycomb. The angle between the central path of the dance and the top of the comb depicts the direction that a recruit must follow, relative to the sun's azimuth (von Frisch 1967). If a hive is placed on its side, bees are forced to dance on a horizontal surface, and thus have no directional reference point, unless an artificial light source is present-in which case, both dancers and recruits realign their reference point to the light (Figure 7.1). Comparisons of the performance of hives with oriented and disoriented dances reveal that direction communication leads to an improved foraging performance only under surprisingly limited circumstances. In one study, oriented dances led to more food being collected in the Californian winter, but not in the summer or autumn (Figure 7.2; Sherman and Visscher 2002). In another study, improved performance was found only in the tropics, but not in temperate Northern European or Mediterranean climates (Dornhaus and Chittka 2004).

Together, these findings suggest that the dance language may be a product of particular ecological circumstances. In the tropical environments where honey bees diversified, trees that produce abundant flowers over a short time window are a major source of forage. In the Californian winter, food patches are also clustered and ephemeral, and the benefits of recruitment are likely to be greater than in areas where herbs and shrubs constitute a major nectar source, as is typical of temperate summers (Heinrich 1979). The suggestion that the value of dance information reflects food patch distribution invites more direct empirical exploration, but such findings provide an enticing glimpse at how ecology may shape communication, perhaps making some headway toward the intriguing question of why no equivalent referential communication system has been found among the other social Hymenoptera. In bumble bees, for example, returning foragers make irregular runs 


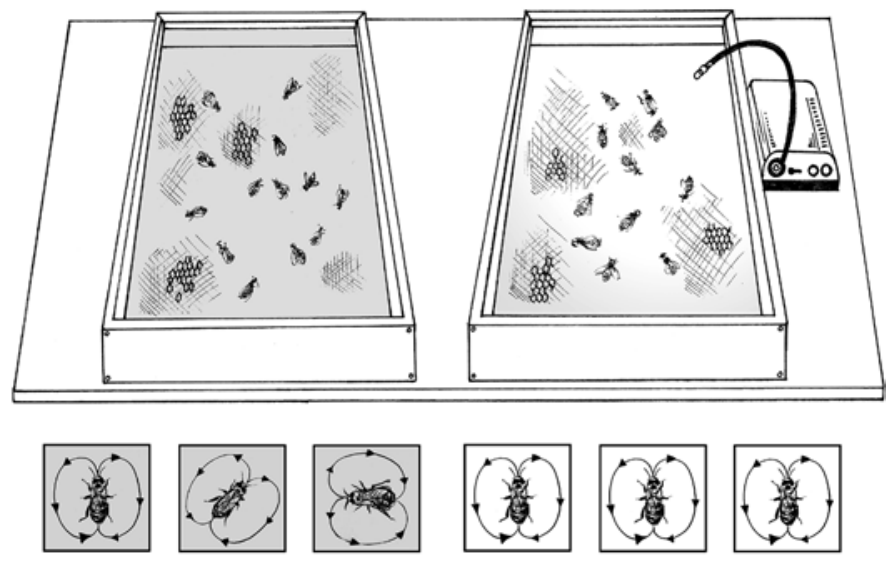

(a)

(b)

FIGURE 7.1 Examples of the orientation of dances of an individual bee (insets at bottom) within a disoriented hive (a), where the dance floor was horizontal and the hive was in complete darkness, and an oriented hive (b), where the dance floor was horizontal but a light source was available, which both dancers and recruits could use as a reference point. (Illustration by Sara Blackburn.)

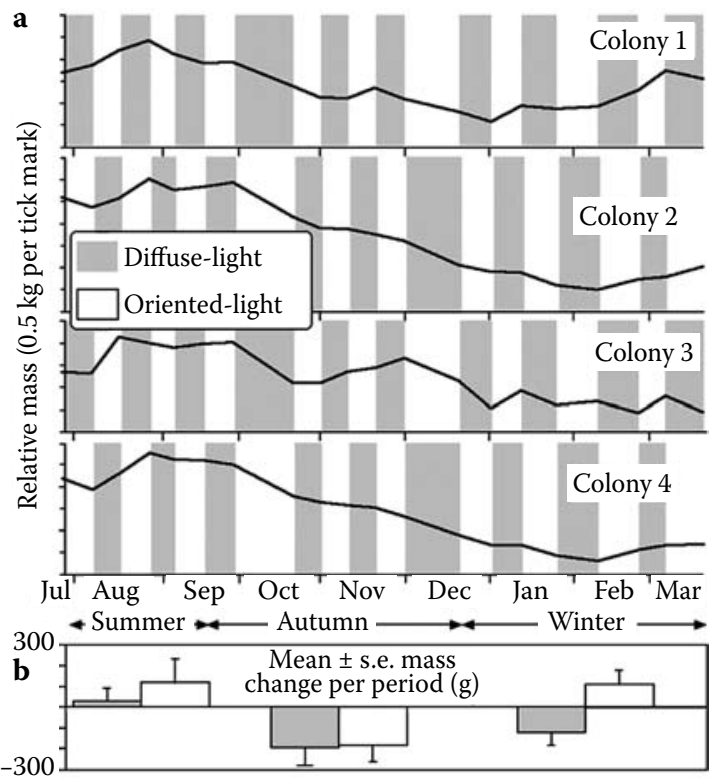

FIGURE 7.2 (a) Mass changes, as an indicator of food intake, in four honey bee colonies with successively oriented and disoriented dances. Bee colonies were aligned horizontally, and alternately allowed to perform oriented (oriented light, unshaded regions) or disoriented (diffuse light, shaded regions) dances for nineteen successive periods over the course of 9 months. (b) Mean mass changes during summer, autumn, and winter when colonies had oriented and disoriented dances. (After Sherman and Visscher 2002. With permission.) 
around the nest, but this serves to distribute a pheromone that elicits foraging behavior, rather than to communicate location (Dornhaus and Chittka 1999, 2001). Stingless bees of some species also perform such irregular runs in the hive. Although the turning and spinning of the foragers in the course of their running vaguely reminds one of the honey bees' dance, it remains controversial whether this behavior, or vibrational signals produced during it, encode the location of a food source (see Chapter 11).

\section{Choosing between Flowers}

Copying the foraging choices of others, or following their signals to find food, inevitably involves exploiting resources that have already been identified and are being harvested (Ruxton et al. 1995). If the value of social information about food location is limited in the context of searching for relatively large food patches, as is illustrated above, it follows that such information should rarely be useful at all when pollinating insects decide between individual inflorescences, which contain tiny volumes of nectar. If individual nectaries are rapidly drained by the foragers that find them, joining conspecifics will be a poor option unless the inflorescences in question contain an unusually large number of flowers. Nonetheless, an attraction to occupied inflorescences has been found in many pollinators, including bumble bees, stingless bees, honey bees, and wasps (Brian 1957; Wenner and Wells 1990; Slaa et al. 2003; Leadbeater and Chittka 2005; Kawaguchi et al. 2007). Why should an apparently maladaptive behavior be so common?

One explanation might be that individuals join each other as an aggressive response, or because they are simply attracted to conspecifics; indeed, bumble bees also tend to land beside conspecifics in a nonforaging context (Leadbeater and Chittka 2007b). Interestingly, however, a number of studies have found that joining behavior often occurs only when foragers visit flower species that they are not familiar with (Slaa et al. 2003; Leadbeater and Chittka 2005; Kawaguchi et al. 2007). Thus, perhaps joining behavior has adaptive benefits for foraging efficiency, not because it leads to individual rewarding flowers, but because it encourages sampling of rewarding flower species that might otherwise be ignored. Indeed, bumble bees that are foraging on one flower species will switch to another, more rewarding alternative more quickly if other bees are foraging there than if alone, because they are attracted to the occupied flowers (Leadbeater and Chittka 2007b). Surprisingly, there is also evidence that bumble bees can learn about rewarding flower species directly through observation of conspecific foragers. When bumble bees were permitted to watch conspecifics foraging on green flowers, and avoiding orange alternatives, observers later showed a significant preference for green when foraging alone (Worden and Papaj 2005).

\section{Tandem Running to Large Food Sources}

Like honey bees in the tropics, many ants forage on foodstuffs that cannot be effectively exploited by one individual, and thus foragers use a plethora of multimodal signals to recruit their nestmates to the patches that they find (Hölldobler and Wilson 1990; Jackson and Ratnieks 2006). A behavior that features in both foraging and house hunting is tandem running, whereby a successful forager effectively leads a naïve follower to a target (Möglich et al. 1974; Hölldobler and Wilson 1990). A tandem run begins when a successful forager or scout recruits potential followers in the nest via food-offering rituals, and once antennal contact is established, the pair proceeds with the follower's antennae placed on the leader's abdomen (Figure 7.3b).

During a run, if the follower loses contact, the leader stops and adopts calling behavior until it is resumed - a feature that has led some authors to describe tandem leading as teaching (Franks and Richardson 2006). Indeed, the leader's behavior probably meets all the criteria of the commonly accepted definition of teaching provided by Caro and Hauser (1992), which states that the candidate behavior must occur only in the presence of a naïve observer, that the teacher must incur a cost (or at least no direct benefit to itself), and that the recipient must consequently acquire information more 
(a)

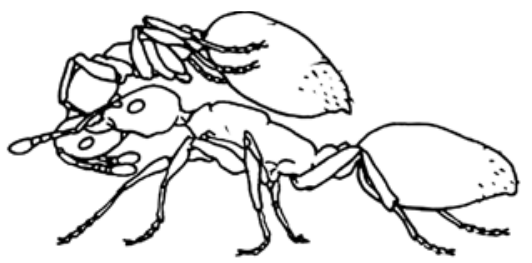

(b)

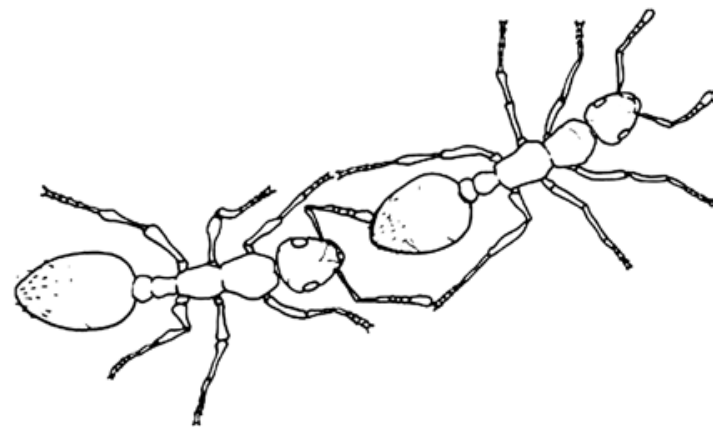

FIGURE 7.3 Ant recruitment. Transport by carrying (a) is faster than tandem running (b), but tandem running offers the advantages that recruits learn the route to the target. (Drawings by Sara Blackburn, based on photographs in Franks et al. 2002.)

quickly than it otherwise would. Tandem leaders incur a cost because the target is reached more slowly (Franks and Richardson 2006), and the follower's presence is a requirement for the pair to continue. It remains to be shown that the follower actually learns the route, rather than simply finding the food, but when tandem running occurs during house hunting, recruits repeatedly return to the target site as new tandem leaders (Möglich and Hölldobler 1974), implying that spatial learning has indeed occurred.

Under such a definition, a number of honey bee behaviors (including trophallaxis between foragers, discussed further in Chapter 10) may also qualify as teaching; however, whether it is useful to use the term teaching in the context of simple, declarative information is a controversial issue (Leadbeater et al. 2006; Csibra 2007; Premack 2007; Richardson et al. 2007; Thornton et al. 2007). Nonetheless, there can be little dispute that tandem running provides a fascinating example of how recruitment strategies are shaped by information requirements. Tandem pairs proceed, on average, four times more slowly than ants that return to food sources alone (Franks and Richardson 2006). Presumably, this investment is worthwhile because, unless the food source can be carried back to the nest by the two ants, the follower needs to learn the route rather than simply arrive at the food source. The trade-off between speed and the need for learning becomes clear when tandem running is considered in a house-hunting context. When scouts find potential nest sites, they lead nestmates to their chosen location via tandem runs, and the follower will then return to the nest and lead runs itself. However, once a threshold number of recruits have been led to the site, ants usually cease to act as leaders and switch to simply carrying their remaining nestmates. Carrying is much faster than tandem running, but recruits are transported upside down (Figure 7.3a), and thus (like passively displaced honey bees; Geiger et al. 1994) cannot learn the route and later become recruiters themselves (Pratt et al. 2002).

\section{Deciding When to Follow Dances}

If animals can be choosy about when they rely on social cues and when they ignore them, then social information use may prove adaptive under a wider range of circumstances than would otherwise be the case (Laland 2004). Indeed, evidence from fish, mammals, and birds suggests that flexibility is 
a prominent feature of many social learning systems, and animals typically rely on social cues only when individual information is unreliable or not available (Laland 2004; Kendal et al. 2005). In insects, such hypotheses have yet to be directly tested, but a number of observations imply that they, too, do not always use social information as a blanket strategy. For example, honey bee foragers are more likely to follow dances before leaving the nest on the first few trips of their foraging career than when experienced. Experienced foragers, on the other hand, apparently rely on memorized information about food source locations rather than using spatial information provided by waggle dancers within the nest, because the simple presence of a dancing bee motivates them to fly to previously visited food patches-irrespective of vector and food odor information (Grüter et al. 2008). However, they tend to follow dances under specific circumstances where information acquired through personal experience has proved unreliable or is out of date-if their previous trip has been unsuccessful, or if they have no up-to-date personal information due to overnight inactivity (Biesmeijer and Seeley 2005).

Such flexibility can be achieved through simple associative learning. If animals modify their behavior according to the negative or positive feedback they receive, then social information use should become closely matched to environmental circumstances (Galef 1995). For example, foraging bumble bees leave chemical "footprints," derived from hydrocarbons that are passively secreted from their cuticle to prevent desiccation, on the flowers that they visit. These marks typically repel both bumble bees and other pollinators from the flowers where they are found, thus leading to avoidance of recently depleted nectar sources (Goulson et al. 1998; Stout et al. 1998; Gawleta et al. 2005; see also Chapter 13). However, if the marks are associated with high rewards, rather than with empty flowers, foragers quickly develop the opposite preference, and begin to treat them as an attractive stimulus (Saleh and Chittka 2006). The question of whether the use of scent marks as social information is entirely learned remains to be addressed, and it would be interesting to know whether naïve bees exhibit unlearned preferences or avoidance behavior toward scent-marked flowers. Nonetheless, it is clear that learning can lead to flexibility within insect social cue use, allowing for a close fit between social information use and environmental circumstances.

\section{INSECT "Traditions"}

So far, we have highlighted the role of social learning as a means to rapidly track short-term changes in the environment. By nature, these behavioral changes are transient; indeed, it is precisely because environments change rapidly and unpredictably that this horizontal transmission of behavior may be adaptive (Laland et al. 1996). However, such short-term responses are notably different in kind from the long-term, cross-generational social habits that we call traditions. Traditions are the product of social learning that is not limited to individuals who utilize the same resources at the same time, but is persistent in time, maintained from generation to generation.

Many social insect colonies persist at the same site for multiple generations before relocating. Honey bee colonies, for example, survive for an average of 5.6 years at the same site under successive queens, if they make it through the first winter (Seeley 1978). Models that examine whether animals should learn behavior socially between (rather than within) generations predict that this type of occasionally changing environment should favor cross-generational social learning -in contrast to very stable environments, which should favor genetic inheritance of behavioral phenotypes, and highly unpredictable environments, where individual learning will be the most adaptive strategy (Boyd and Richerson 1985, 1988).

Traditions are rarely discussed in an invertebrate context (although see Donaldson and Grether 2007), but a series of experiments by Martin Lindauer and his student Wolfgang Kirchner provide grounds to suggest that social learning between insects of different age cohorts at least, if not different generations, may be a feature of social insect societies. In two similar studies, Lindauer (1985) and Kirchner (1987) investigated whether the temporal rhythms of a honey bee colony's foraging workforce, shaped by local environmental conditions, could be transmitted to the larval brood before emergence. They trained groups of foragers to visit highly 
rewarding feeders that were available for only an hour every day, either early in the morning, at midday, or in the evening. Groups of brood cells were then removed from each colony and raised in an incubator. When these bees were subsequently permitted to visit a continuously rewarding feeder, their activity patterns were similar to those of their trained predecessors, closely matching the availability of food in their mother colony. Kirchner (1987) suggests that increased levels of vibrational signaling on the dance floor above the young larvae during periods of heavy recruitment may have mediated this effect, but it seems equally possible the cue responsible may have been more frequent feeding of larvae by nurse bees during times of high food availability.

Whether this form of social learning remains stable over time remains open to question, but Lindauer's and Kirchner's studies pave the way for more detailed investigations of cross-cohort or cross-generational social learning in insects. A further interesting development in the question of invertebrate traditions in general is the suggestion that traditional behavior might arise without the need for learning at all. Donaldson and Grether (2007) argue that the cross-generational use of the same roosting sites by harvestmen, meditated by olfactory cues deposited at those locations, might also be considered traditional, especially given that the sites in question resembled a random sample of those available in terms of microclimate and ecology. The issue of whether this type of behavior, which does not require learning, constitutes a tradition remains open to debate, but the phenomenon described by Donaldson and Grether (2007) is certainly an interesting example of social information use that is unlikely to be limited to harvestmen, but may be widespread within the insects too.

\section{SOCIAL TRANSMISSION OF FORAGING TECHNIQUES}

Behavioral ecologists are interested in social information not only because it may guide decision making, but also because it can lead to the introduction of new, adaptive behaviors into an individual's repertoire. Such processes can have profound implications for a species' ecology, because socially acquired behaviors can spread through a group at an accelerating rate through positive feedback: the more "demonstrators" there are, the more naïve individuals acquire the behavior and become demonstrators themselves (Cavalli-Sforza and Feldman 1981; Pulliam 1983; Boyd and Richerson 1985). Research into how social transmission affects the dynamics of behavior has been limited to vertebrates, and well-cited examples include the social learning of pine cone stripping by black rats in Israel (Terkel 1996), and the spread of potato-washing behavior in Japanese macaques (Kawai 1965). Recently, we found that social transmission processes may be important for the dynamics of insect behavioral phenotypes, too (Leadbeater and Chittka 2008), as we discuss below.

\section{Nectar-Robbing Bumble Bees}

Nectar robbing occurs when pollinators create or reuse holes bitten through the base of a flower to extract nectar (Figure 7.4), rather than entering the corolla and hence pollinating the flower in the "legitimate" manner (Wille 1963; Inouye 1980). We noticed that broad bean plants, grown from seed in the open air, would remain intact for weeks until suddenly, every flower would be robbed over the space of only a few hours (Leadbeater and Chittka 2008). Is the spread of robbing behavior facilitated by positive feedback? The question is interesting from an evolutionary perspective, because robbers exert selection on the mutualistic relationship between flowering plants and pollinators through their varied effects on plant fitness (Maloof and Inouye 2000; Irwin 2006).

In the laboratory, we allowed naïve bees to forage either on unrobbed flowers or on flowers where robbing holes had already been cut. When bees were subsequently allowed to forage alone, on unmanipulated plants, a similar number from both groups showed a tendency to bite the flowers. However, of these, bees that had never previously used the robbing holes bit in the wrong placesaround the petals and the legitimate entrance-and thus were not rewarded by finding the nectar source. In contrast, almost two-thirds of those bees that had acted as secondary robbers successfully 


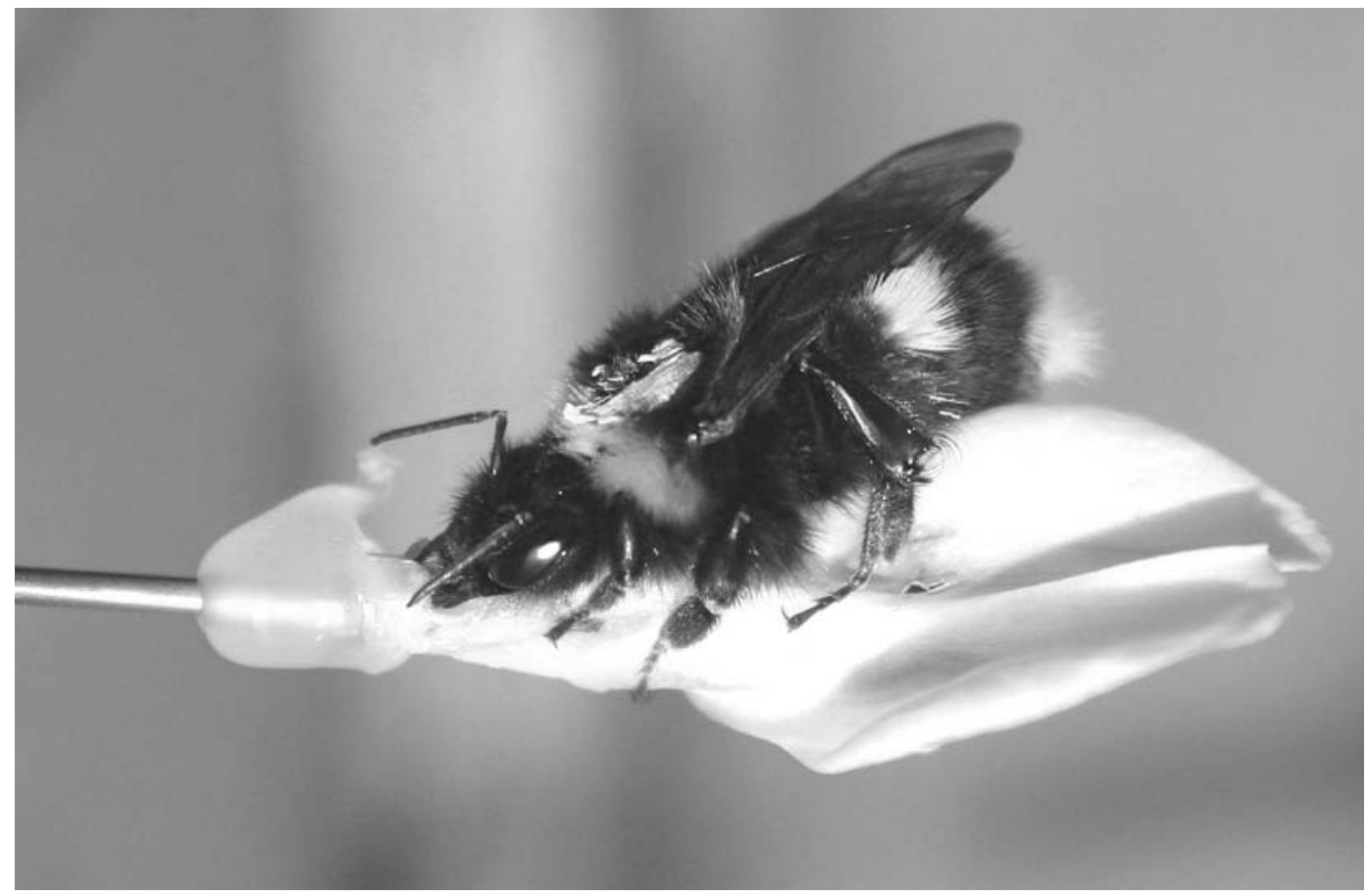

FIGURE 7.4 A bumble bee robbing a broad bean (Vicia faba) flower, mounted on a syringe needle. See color insert following page 142. (Photograph by E. Leadbeater.)

created robbing holes, becoming primary robbers. Just as many apparently complex behavior patterns can be transmitted between individuals through relatively simple inadvertent social information (Danchin et al. 2004), here, the analysis of the behavior of individual bumble bees reveals a straightforward mechanistic explanation. Bees that had experience of using the robbing holes tended to visit the base of the corolla when searching for nectar, and hence biting behavior was more likely to occur in the correct location. A common theme of insect social learning is that there is little temptation to explain social information use in terms of complex cognition; instead, behavioral change reflects simple and yet robust processes by which adaptive behavioral modifications can be achieved. We illustrate this point further in the next section.

\section{SOCIAL INFORMATION ABOUT WHEN NOT TO FORAGE}

An insect that can glean information about danger from others, and modify its foraging behavior accordingly, might bypass the risk of injury or potential death. Thus, social information use should be particularly apparent in the context of predation. In many cases, insects learn about danger through signals produced by their conspecifics; for example, aphid alarm pheromones induce nearby individuals to instantaneously drop from tree branches when their relatives are attacked (Montgomery and Nault 1977; Wohlers 1980). In other cases, however, responses to predation risk are based on information as simple as the presence or absence of conspecifics. For example, harvester ant colonies do not forage every day, but each morning a behaviorally distinct group of workers called patrollers leaves the nest and explores the colony's foraging trails (Gordon 1991). The foraging workforce does not emerge until the patrollers return safely to the nest, and the level of foraging activity that takes place depends upon the rate at which the patrollers come home (Greene and Gordon 2007). 


\section{Classical Conditioning in Damselfiy Antipredator Response}

Some of the best evidence that insects can actually learn about their environment through the fly antipredator response behavior of others comes from the context of predation, and sometimes the learning processes involved are surprisingly complex. In areas where damselflies (Enallagma boreale) co-occur with predatory pike (Esox lucius), their larvae respond to olfactory cues from pike stimuli with antipredator behavior involving a reduction in feeding activity and movement. In contrast, larvae from allopatric populations do not respond to pike cues, but can be induced to do so if such cues are presented in combination with olfactory cues from crushed conspecifics (Wisenden et al. 1997). Wisenden and colleagues found that when the same larvae were later presented with pike cues in the absence of conspecific stimuli, they again reduced their feeding activity and movement, implying that the predation response had become conditioned to the pike stimulus.

This remarkably rapid and apparently complex learning can be explained by simple classical conditioning, although it is sometimes referred to as "observational conditioning" (Cook and Mineka 1989; Heyes 1994). Larvae from both populations showed antipredation responses to the conspecific cues alone; thus it seems likely that when the pike and conspecific cues were presented in combination, this response simply became conditioned to the new stimulus (Figure 7.5; Leadbeater and Chittka 2007a). Similar phenomena might be found in any situation where an animal shows a learned or pre-programmed response to cues from conspecifics that are the subject of predation, although little experimental investigation of this phenomenon has taken place in insects. Furthermore, there is no reason to expect that such learning should occur in response to conspecific cues alone, given that species sharing the same habitat may be at risk from the same predators. Indeed, in the damselfly study, larvae showed the same response when pike stimuli were combined with cues from injured fathead minnows-a taxonomically remote species that is hunted by the same predator (Wisenden et al. 1997).

\section{Long-Term Risk Assessment in Wood Crickets}

A study on wood crickets of the species Neomobius sylvestris (Coolen et al. 2005) provides evidence that insects can also learn about levels of predation risk, rather than predator identity, through their conspecifics' behavior. Juvenile "demonstrator" crickets placed in containers with predatory

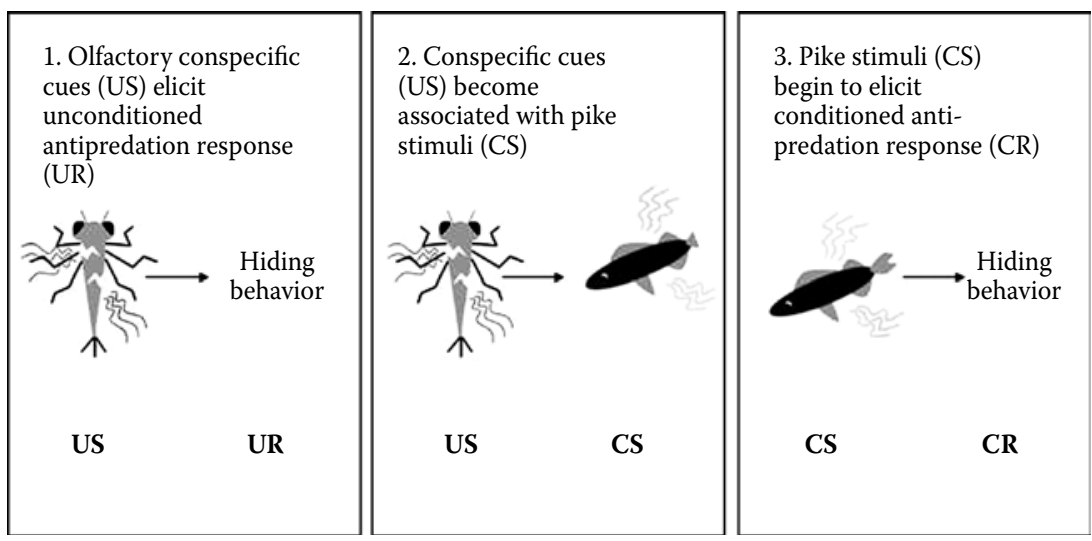

FIGURE 7.5 Classical conditioning of antipredator behavior in damselfly larvae. Larvae exhibit an initial hiding response (unconditioned response, UR) to olfactory cues from injured conspecifics (unconditioned stimulus, US). This response may become conditioned to new stimuli, such as cues produced by predators (conditioned stimulus, CS), if individuals experience both stimuli together. The hiding response thus becomes a conditioned response (CR). (From Leadbeater and Chittka 2007a. With permission.) 
spiders tended to hide under the available leaf litter, even when transferred to new cages devoid of any spider cues. When naïve new companions were introduced into these new cages, they were also significantly more likely to hide under the leaves than crickets introduced into identical control cages, where demonstrators had never experienced spiders (and accordingly were not hiding). This difference in behavior persisted for $24 \mathrm{~h}$ after the demonstrators had been removed, suggesting that the crickets had learned indirectly about local predation risk through the behavior of their conspecifics.

\section{CONCLUDING REMARKS}

We began this chapter with the claim that social information use in the small-brained insects is surprisingly complex. Perhaps, however, one of the most consistent messages to emerge from the studies that we have discussed above is that the mechanistic basis for such behavior is surprisingly simple. When one is dealing with a relatively miniscule nervous system, there is little temptation to explain behavior in terms of advanced cognition without looking for simpler explanations first. Thus, even damselfly larvae can learn socially about predator identity through simple Pavlovian mechanisms, and ant societies can assess threat levels on the straightforward basis of whether their conspecifics make it home. Bumble bees pick up "bad habits" from others, learning to rob plants simply because they use the holes that other bees leave behind, and ants inform each other about where to find food just by walking others through the process, rather than carrying them there.

So what can these straightforward, yet highly effective social information systems offer to those interested in why social information use increases biological competitiveness? In writing this chapter, we hope to go some way toward providing a bridge between the empirical study of insect social systems and theoretical predictions about the usefulness of social information. The social insects, particularly, are unusual in that inadvertent social information has often evolved into specialized signals, and this "packaging" offers opportunities for experimental manipulation that are perhaps unparalleled in the vertebrate world. To date, few adaptive hypotheses have been tested using insect models. Yet the studies described above hint that insect social information systems have indeed been shaped by selection for reliability and cost-effectiveness, and they invite more direct development of this approach. Insects may have small brains, but they may also provide a relatively untapped system for understanding how social information use and social learning begin to evolve.

\section{REFERENCES}

Biesmeijer JC, Seeley TD. (2005). The use of waggle dance information by honey bees throughout their foraging careers. Behav Ecol Sociobiol 59:133-42.

Boyd R, Richerson PJ. (1985). Culture and the Evolutionary Process. Chicago: University of Chicago Press.

Boyd R, Richerson PJ. (1988). An evolutionary model of social learning: The effects of spatial and temporal variation. In Zentall TR, Galef BG (eds.), Social Learning: Psychological and Biological Perspectives. Hillsdale, NJ: Lawrence Erlbaum Associates, pp. 29-48.

Brian AD. (1957). Differences in the flowers visited by four species of bumble-bees and their causes. J Anim Ecol 26:71-98.

Caro TM, Hauser MD. (1992). Is there teaching in nonhuman animals? Q Rev Biol 67:151-74.

Cavalli-Sforza LL, Feldman MW. (1981). Cultural Transmission and Evolution: A Quantitative Approach. Princeton, NJ: Princeton University Press.

Cook M, Mineka S. (1989). Observational conditioning of fear to fear-relevant and fear-irrelevant stimuli in rhesus monkeys. J Abnorm Psychol 98:448-59.

Coolen I, Dangles O, Casas J. (2005). Social learning in noncolonial insects? Curr Biol 15:1931-35.

Csibra G. (2007). Teachers in the wild. Trends Cogn Sci 11:95-96.

Danchin E, Giraldeau LA, Valone TJ, Wagner RH. (2004). Public information: From nosy neighbours to cultural evolution. Science 305:487-91.

Dechaume-Moncharmont FX, Dornhaus A, Houston AI, McNamara JM, Collins EJ, Franks NR. (2005). The hidden cost of information in collective foraging. Proc R Soc Lond B 272:1689-95. 
Donaldson ZR, Grether GF. (2007). Tradition without social learning: A scent-based communal roost formation in a Neotropical harvestman (Prionostemma sp.). Behav Ecol Sociobiol 61:801-9.

Dornhaus A, Chittka L. (1999). Evolutionary origins of bee dances. Nature 401:38.

Dornhaus A, Chittka L. (2001). Food alert in bumblebees (Bombus terrestris): Possible mechanisms and evolutionary implications. Behav Ecol Sociobiol 50:570-76.

Dornhaus A, Chittka L. (2004). Why do honeybees dance? Behav Ecol Sociobiol 55:395-401.

Dornhaus A, Klügl F, Oechslein C, Puppe F, Chittka L. (2006). Benefits of recruitment in honey bees: Effects of ecology and colony size in an individual-based model. Behav Ecol 17:336-44.

Dyer FC. (2002). The biology of the dance language. Annu Rev Entomol 47:917-49.

Franks NR, Pratt SC, Mallon EB, Britton NF, Sumpter DJT. (2002). Information flow, opinion polling and collective intelligence in house-hunting social insects. Phil Trans $R$ Soc Lond B 357:1567-83.

Franks NR, Richardson T. (2006). Teaching in tandem-running ants. Nature 439:153.

von Frisch K. (1967). The Dance Language and Orientation of Bees. Cambridge, MA: Harvard University Press.

Galef BJ. (1995). Why behaviour patterns that animals learn socially are locally adaptive. Anim Behav 49:1325-34.

Gawleta N, Zimmermann Y, Eltz T. (2005). Repellent foraging scent recognition across bee families. Apidologie 36:325-30.

Geiger K, Kratzsch D, Menzel R. (1994). Bees do not use landmark cues seen during displacement for displacement compensation. Naturwissenschaften 81:415-17.

Giraldeau LA, Beauchamp G. (1999). Food exploitation: Searching for the optimal joining policy. Trends Ecol Evol 14:102-6.

Giraldeau LA, Valone TJ, Templeton JJ. (2002). Potential disadvantages of using socially acquired information. Phil Trans R Soc Lond B 357:1559-66.

Giurfa M. (2003). The amazing mini-brain: Lessons from a honey bee. Bee World 84:5-18.

Gordon DM. (1991). Behavioral flexibility and the foraging ecology of seed-eating ants. Am Nat 138:379-411.

Goulson D, Hawson SA, Stout JC. (1998). Foraging bumblebees avoid flowers already visited by conspecifics or by other bumblebee species. Anim Behav 55:199-206.

Greene MJ, Gordon DM. (2007). Interaction rate informs harvester ant task decisions. Behav Ecol 18:451-55.

Grüter C, Sol Balbuena M, Farina WM. (2008). Informational conflicts created by the waggle dance. Proc $R$ Soc B 275:1321-27.

Heinrich B. (1979). Bumblebee Economics. Cambridge, MA: Harvard University Press.

Heyes CM. (1994). Social learning in animals: Categories and mechanisms. Biol Rev 69:207-31.

Hölldobler B, Wilson EO. (1990). The Ants. Cambridge, MA: Harvard University Press.

Inouye DW. (1980). The terminology of floral larceny. Ecology 61:1251-53.

Irwin RE. (2006). The consequences of direct versus indirect species interactions to selection on traits: Pollination and nectar robbing in Ipomopsis aggregata. Am Nat 167:315-28.

Jackson DE, Ratnieks FLW. (2006). Communication in ants. Curr Biol 16:R570-74.

Kawaguchi LG, Ohashi K, Toquenaga Y. (2007). Contrasting responses of bumble bees to feeding conspecifics on their familiar and unfamiliar flowers. Proc R Soc Lond B 274:2661-67.

Kawai M. (1965). Newly-acquired pre-cultural behavior of the natural troop of Japanese monkeys on Koshima islet. Primates 6:1-30.

Kendal RL, Coolen I, van Bergen Y, Laland KN. (2005). Trade-offs in the adaptive use of social and asocial learning. Adv Stud Behav 35:333-79.

Kirchner WH. (1987). Tradition im Bienenstaat: Kommunikation zwischen den Imagines und der Brut der Honigbiene durch Vibrationssignale. Doctoral thesis, University of Würzburg, Germany.

Laland KN. (2004). Social learning strategies. Learn Behav 32:4-14.

Laland KN, Richerson PJ, Boyd R. (1996). Developing a theory of animal social learning. In Heyes CM, Galef BG (eds.), Social Learning in Animals: The Roots of Culture. San Diego: Academic Press, pp. 129-54.

Leadbeater E, Chittka L. (2005). A new mode of information transfer in foraging bumblebees? Curr Biol 15:R447-48.

Leadbeater E, Chittka L. (2007a). Social learning in insects-From miniature brains to consensus building. Curr Biol 17:R703-13.

Leadbeater E, Chittka L. (2007b). The dynamics of social learning in an insect model, the bumblebee (Bombus terrestris). Behav Ecol Sociobiol 61:1789-96. 
Leadbeater E, Chittka L. (2008). Social transmission of nectar-robbing behaviour in bumble-bees. Proc R Soc B 275:1669-74.

Leadbeater E, Raine NE, Chittka L. (2006). Social learning: Ants and the meaning of teaching. Curr Biol 16:R323-25.

Lindauer M. (1985). The dance language of honeybees: The history of a discovery. In Hölldobler B, Lindauer M (eds.), Experimental Behavioral Ecology and Sociobiology: In Memoriam Karl von Frisch 18861982. Sunderland: Sinauer, pp. 129-40.

Lubbock J. (1882). Ants, Bees and Wasps: A Record of Observations on the Habits of the Social Hymenoptera. New York: Appleton.

Maloof JE, Inouye DW. (2000). Are nectar robbers cheaters or mutualists? Ecology 81:2651-61.

Menzel R, Leboulle G, Eisenhardt D. (2006). Small brains, bright minds. Cell 124:237-39.

Möglich M, Hölldobler B. (1974). Social carrying behaviour and division of labor during nest moving in ants. Psyche 81:219-36.

Möglich M, Maschwitz U, Hölldobler B. (1974). Tandem calling: A new kind of signal in ant communication. Science 186:1046-47.

Montgomery ME, Nault LR. (1977). Comparative response of aphids to alarm pheromone, (E)-beta-farnesene. Entomol Exp Appl 22:236-42.

Nieh JC, Barreto LS, Contrera FAL, Imperatriz-Fonseca VL. (2004). Olfactory eavesdropping by a competitively foraging stingless bee, Trigona spinipes. Proc R Soc Lond B 271:1633-40.

Pratt SC, Mallon EB, Sumpter DJT, Franks NR. (2002). Quorum sensing, recruitment, and collective decision-making during colony emigration by the ant Leptothorax albipennis. Behav Ecol Sociobiol 52:117-27.

Premack D. (2007). Human and animal cognition: Continuity and discontinuity. Proc Natl Acad Sci USA 104:13861-67.

Pulliam HR. (1983). On the theory of gene-culture co-evolution in a variable environment. In Melgren RL (ed.), Animal Cognition and Behavior. Amsterdam: North-Holland Publishing Company, pp. 427-43.

Richardson TO, Sleeman PA, McNamara JM, Houston AI, Franks NR. (2007). Teaching with evaluation in ants. Curr Biol 17:1520-26.

Ruxton GD, Hall SJ, Gurney WSC. (1995). Attraction toward feeding conspecifics when food patches are exhaustible. Am Nat 145:653-60.

Saleh N, Chittka L. (2006). The importance of experience in the interpretation of conspecific chemical signals. Behav Ecol Sociobiol 61:215-20.

Seeley TD. (1978). Life history strategy of the honey bee, Apis mellifera. Oecologia 32:109-18.

Sherman G, Visscher PK. (2002). Honeybee colonies achieve fitness through dancing. Nature 419:920-22.

Slaa JE, Wassenberg J, Biesmeijer JC. (2003). The use of field-based social information in eusocial foragers: Local enhancement among nestmates and heterospecifics in stingless bees. Ecol Entomol 28:369-79.

Spitzner MJE. (1788). Ausführliche Beschreibung der Korbbienenzucht im sächsischen Churkreise, ihrer Dauer und ihres Nutzens ohne künstliche Vermehrung nach den Gründen der Naturgeschichte und nach eigener langer Erfahrung. Leipzig: Junius.

Stout JC, Goulson D, Allen JA. (1998). Repellent scent-marking of flowers by a guild of foraging bumblebees (Bombus spp.). Behav Ecol Sociobiol 43:317-26.

Terkel J. (1996). Cultural transmission of feeding behaviour in the black rat (Rattus rattus). In Heyes CM, Galef BG (eds.), Social Learning in Animals: The Roots of Culture. San Diego: Academic Press, pp. 17-47.

Thornton A, Raihani NJ, Radford AN. (2007). Teachers in the wild: Some clarification. Trends Cogn Sci 11:272-73.

Wenner AM, Wells PH. (1990). Anatomy of a Controversy: The Question of a "Language" among Bees. New York: Columbia University Press.

Wille A. (1963). Behavioral adaptations of bees for pollen collecting from Cassia flowers. Rev Biol Trop 11:205-10.

Wisenden BD, Chivers DP, Smith RJF. (1997). Learned recognition of predation risk by Enallagma damselfly larvae (Odonata, Zygoptera) on the basis of chemical cues. J Chem Ecol 23:137-51.

Wohlers P. (1980). Escape responses of pea aphids Acyrthosiphon pisum to alarm pheromones and additional stimuli. Entomol Exp Appl 27:156-68.

Worden BD, Papaj DR. (2005). Flower choice copying in bumblebees. Biol Lett 1:504-7. 